\title{
SELECTION PROCESS OF MUNICIPALITIES FOR THE IMPLEMENTATION OF SENAI OPERATING UNITS USING MULTICRITERIA DECISION ANALYSIS
}

\begin{abstract}
The National Industrial Education Service ("Serviço Nacional de Aprendizagem Industrial" - SENAI) is the largest institution of technical education in Latin America. One of its guidelines is increasingly offering professional education in all states of Brazil, which in turn requires the expansion of its service network. The investment for the implementation of a new unit of SENAI is high and generates several political and management problems. Thus, the choice of the municipality for deployment should be based on clearly defined criteria and on a consistent methodology. This paper aims to choose the municipalities for the implementation of new units of SENAI in the State of Espirito Santo, Brazil. We use the Analytic Hierarchy Process Sort (AHPSort) for classification of municipalities considering an economic scenario, and the Analytic Hierarchy Process (AHP) for ranking the municipalities within the priority class for the selection.
\end{abstract}

Keywords: AHP method; AHP Sort method; multicriteria decision making method.

\section{Introduction}

National Industrial Education Service - SENAI, through the Program of Support to the Brazilian Industry Competitiveness, promotes the creation of Institutes of Innovation, Institutes of Technology, Professional Education Centres and Professional Education Mobile Units. The implementation of this process is to be completed by the end of 2017. SENAI aims to train qualified personnel to generate knowledge, develop technologies and meet the manpower according to current and future needs of the industry.

\section{Objectives}

The objective of this paper is to define the municipalities where new SENAI units will be installed in the state of Espirito Santo, Brazil.

\section{Methodology}

The model identification municipalities has two phases. In Phase 1, the multicriteria AHP Sort method was used for classification of municipalities, considering the economic scenario. In Phase 2, the Analytic Hierarchy Process was used for ranking the municipalities within the priority class for the selection of a new professional education center SENAI. Phase 1 begins with the problem structuring defining the criteria, alternatives and classes. The criteria and a partial list of the alternatives are specified in figure 1. The alternatives are the 69 municipalities of the State of Espirito Santo. The 
classes Priority, Optional and Unnecessary are related to the relevance of the implementation of a new unit of SENAI. The limiting profiles are presented in figure 2.

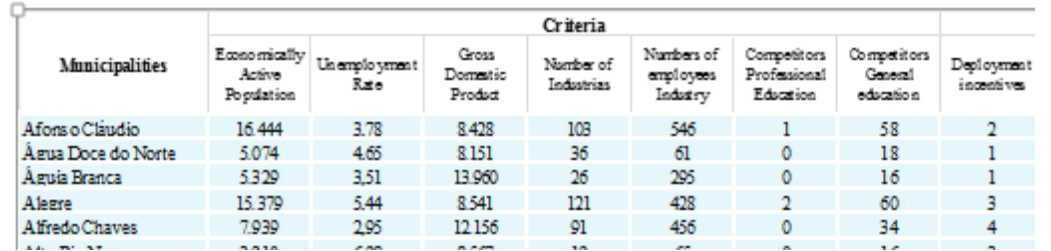

Figure 1: Criteria and alternatives of the AHP Sort

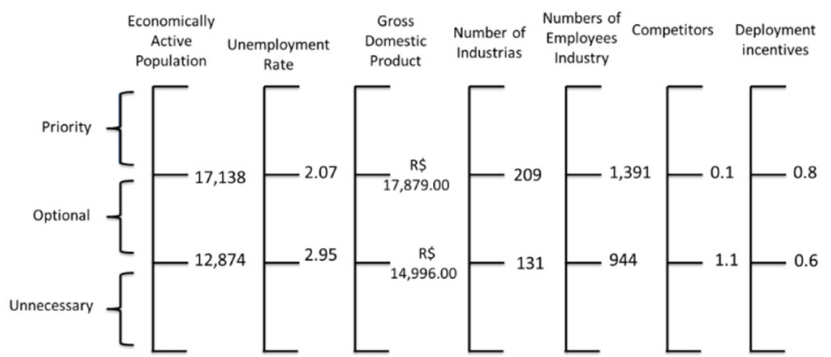

Figure 2: Limiting profiles

The results of Phase 1 indicate eight municipalities in the priority class: Barra de São Francisco; Cariacica; Castelo; Guarapari; Nova Venécia; Santa Maria de Jetibá; São Gabriel da Palha; and Viana.

In Phase 2 the same criteria were considered. The judgments from the stakeholders were in consensus. The municipality of Cariacica was selected since it presented the most favorable criteria regarding a scenario for economic growth as well as long term sustainability.

\section{Conclusions}

The results were coherent with the decision makers thinking in SENAI. Should the traditional AHP be used, the number of pairwise comparisons (16.422) would turn that method unfeasible. The use of AHPSort has led to an impressive decrease in the number of comparisons (138) in the classification phase.

With AHPSort, there are not pairwise comparisons among the alternatives, only comparisons between alternatives and limiting profiles. Therefore, the probability to have inconsistencies will be small.

\section{Key References}

Ishizaka, A., Pearman, C., Nemery, P. (2012). AHP Sort: an AHP-based method for sorting problems. International Journal of Production Research, 50 (17), 4767-4784.

Ishizaka, A., \& Nemery, P. (2013) Multi-criteria decision analysis: methods and software. John Wiley \& Sons Ltd.

Saaty, T. L. (2008) Decision making with the analytic hierarchy process. International Journal of Services Sciences, 1 (1), 83-98. 